\title{
Population Dynamics, Disturbance, and Pattern Evolution: Identifying the Fundamental Scales of Organization in a Model Ecosystem
}

\author{
Thorsten Wiegand, ${ }^{1, \star}$ Kirk A. Moloney, ${ }^{2, \dagger}$ and Suzanne J. Milton ${ }^{3 \ngtr}$
}

1. Department of Ecological Modelling, UFZ-Centre for Environmental Research, Leipzig-Halle, Permoserstrasse 15, 04318 Leipzig, Germany;

2. Department of Botany, 143 Bessey Hall, Iowa State University, Ames, Iowa 50011;

3. FitzPatrick Institute, University of Cape Town, 7700

Rondebosch, South Africa

Submitted August 11, 1997; Accepted March 2, 1998

AвSTRACT: We used auto- and cross-correlation analysis and Ripley's $K$-function analysis to analyze spatiotemporal pattern evolution in a spatially explicit simulation model of a semiarid shrubland (Karoo, South Africa) and to determine the impact of small-scale disturbances on system dynamics. Without disturbance, local dynamics were driven by a pattern of cyclic succession, where "colonizer" and "successor" species alternately replaced each other. This results in a strong pattern of negative correlation in the temporal distribution of colonizer and successor species. As disturbance rates were increased, the relationship shifted from being negatively correlated in time to being positively correlated-the dynamics became decoupled from the ecologically driven cyclic succession and were increasingly influenced by abiotic factors (e.g., rainfall events). Further analysis of the spatial relationships among colonizer and successor species showed that, without disturbance, periods of attraction and repulsion between colonizer and successor species alternate cyclically at intermediate spatial scales. This was due to the spatial "memory" embedded in the system through the process of cyclic succession. With the addition of disturbance, this pattern breaks down, although there is some indication of increasing ecological organization at broader spatial scales. We suggest that many of the insights that can be gained through spatially explicit models will only be obtained through a direct analysis of the spatial patterns produced.

\footnotetext{
*E-mail: towi@oesa.ufz.de.

$\dagger$ E-mail: kmoloney@iastate.edu.

‡E-mail: wdean@uctvms.uct.ac.za.

Am. Nat. 1998. Vol. 152, pp. 321-337. (C) 1998 by The University of Chicago. 0003-0147/98/5203-0001\$03.00. All rights reserved.
}

Keywords: individual-based model, disturbance, Karoo shrubland, Ripley's $K$ function, spatiotemporal dynamics, correlation analysis.

Disturbance is a major factor affecting the spatial structure and temporal dynamics of ecological systems (Pickett and White 1985). For example, small-scale disturbances that remove individuals from a local plant community can reset small patches of vegetation to an earlier successional state (e.g., Hobbs and Mooney 1985; Lawton and Putz 1988; Busing 1995; Moloney and Levin 1996), disrupt patterns of dominance (e.g., Platt 1975; Brokaw and Scheiner 1989; Martinsen et al. 1990; McConnaughy and Bazzaz 1990), provide local opportunities for germination and recruitment (e.g., Chambers et al. 1990; Dean and Milton 1991; Dean and Yeaton 1992; Dean et al. 1994; Lavorel et al. 1994a; Aguilera and Lauenroth 1995), increase the temporal turnover rate of species during succession, increase local species diversity (e.g., Levin and Paine 1974; Huston 1979; Paine and Levin 1981; Martinsen et al. 1990; Reice 1995), allow for more rapid invasion by alien species and weeds (Bergelson et al. 1993), and/or desynchronize recruitment in populations of long-lived plants (e.g., Smith et al. 1994; Schwinning and Parsons 1996). Although we have a fairly well-developed understanding of the short-term impact of disturbance on the temporal and spatial dynamics of ecological systems, our understanding of long-term impacts is still quite limited. This is due primarily to the typical timescales over which ecological dynamics take place, which are usually much longer than the timescales of ecological studies. It is also due to the lack of a sufficient theoretical understanding of disturbance and its ecological effects (although, see Armstrong 1988; Moloney and Levin 1996).

Recent developments in the field of simulation modeling are now providing a means for exploring the longterm dynamics of ecological systems, where complex in- 


\section{The American Naturalist}

teractions occur in both a temporal and a spatial context. One class of spatially explicit model that is proving to be useful in the investigation of spatiotemporal dynamics is the so-called grid-based simulation model (e.g., Silvertown et al. 1992; Colasanti and Grime 1993; Jeltsch and Wissel 1994; Lavorel et al. 1994b; Wiegand et al. 1995; Jeltsch et al. 1996; Moloney and Levin 1996). Gridbased models focus on processes and mechanisms, within a spatial context, that drive community dynamics at the level of the individual plant or of the plant assemblage. Typically, space is modeled as a square grid of cells. Each cell can be associated with specific environmental conditions and can contain one or more individual plants and/ or animals. For plant communities, these models can incorporate short-term knowledge about environmentdependent life-history attributes (e.g., growth, seed production, germination, recruitment, and mortality factors), seed dispersal, disturbance, and local interactions between species (within and among grid cells) into a computer simulation model using a set of simple rules. The models then simulate, on large temporal and spatial scales, the fate of individual plants or plant assemblages within the community; in short, the model produces a characterization of landscape-level community dynamics (Wiegand et al. 1995). In this way, grid-based models are able to close the gap between the short-term knowledge available through observation and experimentation and the need to develop an understanding of long-term community dynamics. An advantage of grid-based simulation models is that they can include the necessary biological information for the modeled processes in the form of rules rather than mathematical equations. This is particularly important for more complex problems, as it allows the direct inclusion of expert knowledge that is not necessarily based on hard data (for this rule-based approach, see also Jeltsch and Wissel 1994; Wiegand et al. 1995; Jeltsch et al. 1996).

Because grid-based models keep track of the state of each cell in the landscape at each time step, they make direct predictions of the spatial and temporal distribution (spatiotemporal pattern) of ecologically important variables, such as species abundances, nutrient availabilities, and community-level diversity. This produces a huge amount of data, either in the form of spatially explicit distribution maps or a time series depicting the average landscape-level response over an entire model run. This type of information is essential for determining how locally occurring ecological processes interact to produce spatiotemporal patterns at a broader spatial and/or temporal scale (Levin 1992).

Although there have been major advances in the field of statistical pattern analysis over the last decade or so (Ripley 1976; Cressie 1991; Rossi et al. 1992; Venables and Ripley 1994; Bailey and Gatrell 1995; Haase 1995), which have been increasingly employed in field-oriented studies (e.g., Mateos 1987; Robertson et al. 1988; Casas 1990; Dessaint et al. 1991; Bradshaw and Spies 1992; Gross et al. 1995; Schlesinger et al. 1996), the use of statistical pattern analysis has in many ways been overlooked in the development of spatially explicit simulation models and in the interpretation of their output (although, see Slatkin and Arter 1991; Moloney et al. 1992; Li and Reynolds 1994). This is curious, particularly since these models are developed explicitly for the study of spatial processes and the data they produce are ideally suited for statistical pattern analysis, employing techniques such as autocorrelation analysis, cross-correlation analysis, semivariance analysis, and Ripley's K-function analysis.

In this article, we will show how advanced pattern analysis techniques can be used to analyze the output of spatially explicit simulation models. We use a previously developed, spatially explicit, individual-based simulation model (Wiegand et al. 1995, 1997) and investigate systematically the impact of disturbance on the temporal and spatial dynamics of a semiarid plant community. The model simulates small-scale disturbances and the dynamics of five dominant species in a semiarid shrubland in the Karoo of South Africa and delivers long-term spatiotemporal data. We employ correlation analysis of the time series and Ripley's $K$-function analysis of the vegetation maps produced by the model to study how disturbance might act to break the well-developed, cyclic, successional relationships between species in this community. We also show how disturbance might alter the evolution of spatiotemporal ecological patterns.

\section{Site Description}

The model used in this study is based on the ecological dynamics occurring at the Tierberg Karoo Research Center $\left(30^{\circ} 10^{\prime} \mathrm{S}, 22^{\circ} 17^{\prime} \mathrm{E}\right)$, within a semiarid shrubland community typical of a large area of the southern part of the Great Karoo, South Africa. (See Milton et al. 1992 and Wiegand et al. 1995 for a detailed description of the system.) Five shrub species dominate the vegetation at the Tierberg site. These are Brownanthus ciliatus (Mesembryanthemaceae), a nonwoody, deciduous, short-lived, matforming succulent; Ruschia spinosa (Ruschioideae), a multistemmed, evergreen leaf succulent; and three nonsucculent species, namely, the semideciduous Galenia fruticosa (Aizoaceae), the deciduous Osteospermum sinuatum (Asteraceae), and the evergreen Pteronia pallens (Asteraceae).

Local dynamics at the Tierberg site are generally characterized by a pattern of cyclic succession (Yeaton and 


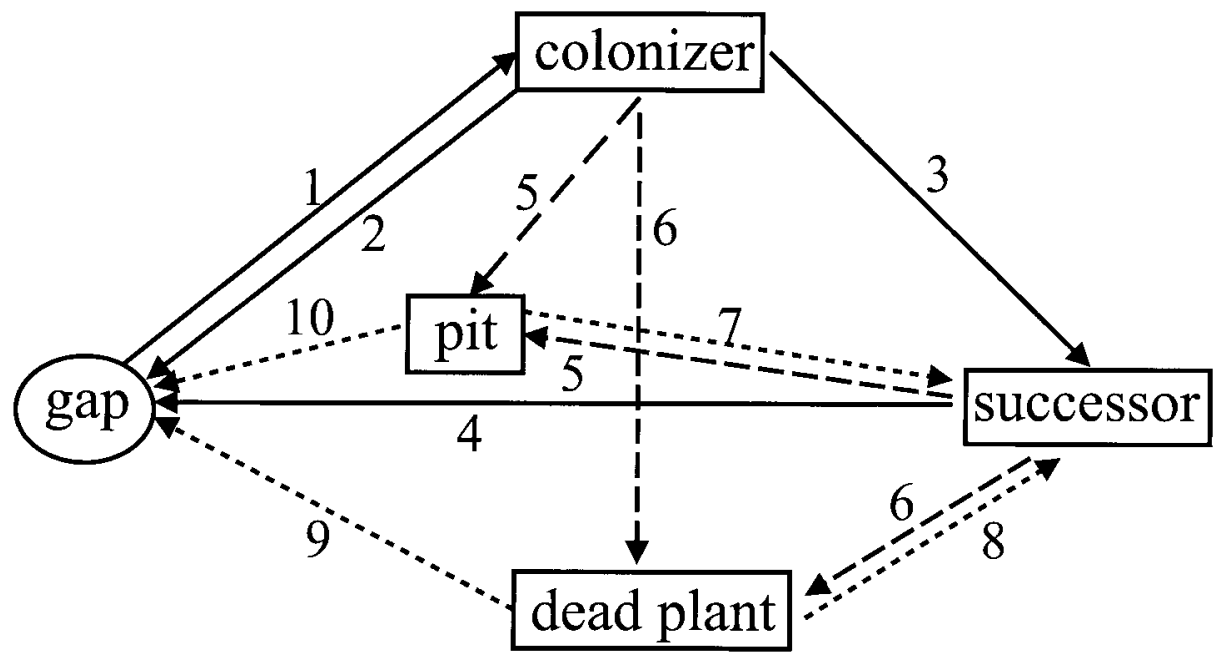

Figure 1: The states and transitions of the Karoo shrubland plant community simulation model. Transitions produced through different mechanisms are symbolized as follows: solid arrows indicate transitions produced through the processes associated with the standard pathway of cyclic succession; large dashed arrows show transitions that are produced by the direct impact of disturbance; and small dashed arrows show transitions produced through processes subsequent to disturbance (e.g., formation of pits). The numbers associated with each arrow indicate the process involved in each transition: 1 = gap colonized by colonizer plant; 2 $=$ gap produced by death of colonizer plant; $3=$ establishment of successor plant within the canopy of a colonizer plant; $4=$ gap produced by the death of a successor plant; $5=$ pit produced by the uprooting of an established plant; $6=$ a standing dead plant produced by a disturbance killing the plant but not uprooting it; $7=$ establishment of a successor plant in a pit; $8=$ establishment of a successor plant beneath a rooted, dead plant; $9=$ gap produced after the decay of a dead plant (10 yr after disturbance); and $10=$ a gap produced after the erosion of a pit (1 yr after disturbance).

Esler 1990; fig. 1). Open sites (gaps) are first colonized by plants of the "colonizer" species B. ciliatus, G. fruticosa, and $R$. spinosa. Once the colonizer plants begin to senesce, seedlings of the "successor" species $P$. pallens and O. sinuatum can establish in the shaded sites found under the canopies of the senescing colonizers. Eventually, after the death of a successor plant, a site becomes unoccupied and can then be reoccupied by a colonizer plant, starting the pattern of cyclic succession over again.

The typical pattern of cyclic succession can be disrupted by small-scale disturbances caused by digging animals. This activity can kill established plants and change the successional pathway. The way in which the successional pathway is changed depends on the life-history attributes of the species affected and the type of disturbance. Disturbances at the Tierberg site are mostly created by aardvarks (Orycteropus afer), which frequently "prospect" for ants and termites by digging shallow scoops in the soil (Dean and Milton 1991; Dean and Yeaton 1992; Wiegand et al. 1997). The mean aardvark disturbance rate at the study site has been determined to be $5.3 /$ ha/year $(\approx 0.05 \%$ of the area disturbed per year; Dean and Yeaton 1992; Wiegand et al. 1997).

The digging activity by aardvarks can destroy nearby seedlings and established shrubs and can change the successional pathway of the plant community in a number of ways (fig. 1). Uprooted dead plants are blown away soon after a disturbance has occurred. The excavated areas that remain behind accumulate wind-blown and water-borne organic and inorganic material and provide shaded establishment sites for the successor species $P$. pallens and $O$. sinuatum. Wind activity and runoff following heavy rain eventually smooth away the excavations within $1 \mathrm{yr}$, and the remaining gaps provide establishment sites for the colonizer species B. ciliatus, G. fruticosa, and R. spinosa. If the dead shrubs are not totally uprooted, they remain in situ for several years and accumulate wind-blown detritus, including large winged seeds of $P$. pallens and $O$. sinuatum, insect frass, and mammal dung. They also provide shaded establishment sites for successor plants. With advancing decay, rooted dead plants eventually lose their ability to trap seeds and organic matter and the site can no longer be invaded by successor plants.

\section{The Model}

We used the site characteristics described above to develop a spatially explicit, grid-based model that simulates small-scale disturbances and the ecological dynamics of the five dominant shrub species at the Tierberg study site. The model follows the fate of each individual plant 


\section{The American Naturalist}

within the plant community throughout its life, simulating the life-history events of seed production, seed dispersal, germination, competition for safe sites, establishment, growth, and mortality. Results of earlier versions of the model have been presented elsewhere (Wiegand et al. 1995; Wiegand and Milton 1996). The model has since been modified to allow for a systematic exploration of the impact of disturbance on community dynamics (Wiegand et al. 1997). A brief description of the model and its rules follows, with further details available in previous studies (Wiegand et al. 1995; Wiegand and Milton 1996; Wiegand et al. 1997).

\section{General Model Structure}

The simulation model is hierarchical in design, being constructed at two basic organizational scales, local and landscape. At the landscape scale, an area of approximately $453 \mathrm{~m}^{2}$ is subdivided into a grid of $77 \times 53$ cells, making individual cells $0.33 \mathrm{~m} \times 0.33 \mathrm{~m}$ in size. The size of an individual cell corresponds approximately to an area occupied by a single adult plant. At the local scale, the model dynamics are based on the processes and mechanisms that determine the state of each cell, that is, whether it is an unoccupied gap or is occupied by seeds, seedlings, a living shrub, or a dead shrub. Changes in the state of a cell depend on the previous state of the cell, the state of neighboring cells across different interaction ranges, and external factors, such as climate and disturbance, which are also explicitly included in the model.

Several demographic processes at the Tierberg site are dependent on the availability of water (Milton 1994, $1995 a, 1995 b)$. In the model, this is accounted for through the SEED submodel, which uses monthly rainfall data to determine the total number of seeds produced, the number of seeds germinating, and seedling survival on a monthly basis during a model run. Certain thresholds of rainfall (which differ from species to species) are required for each of these demographic processes to be successfully completed. The rainfall data used in the model were obtained from actual rainfall records (Prince Albert Jail, unpublished data) or they were produced by the rainfall simulation model GENRAIN (Zucchini et al. 1992). GENRAIN is parameterized from the monthly mean and variance of long-term rainfall records obtained from weather stations near the site being modeled. GENRAIN generates a stochastic time series of monthly rainfall amounts with the same monthly mean and variance as the original data.

Seeds are dispersed in the model using a weighted, random distribution based on empirical data. The small water-dispersed seeds of colonizer species move up to eight cells $(\approx 3 \mathrm{~m})$ away from the source cell and can only successfully germinate if they end up in an empty cell; otherwise they are deleted from the model. Tumbleseeds of the successor plants Pteronia pallens and Osteospermum sinuatum move longer distances, up to 30 and $50 \mathrm{~m}$, respectively, and can be trapped by established colonizer plants, by pits created through the activity of aardvarks (disturbances), or by dead plants. Since the successor species $P$. pallens and $O$. sinuatum have no seedbank (Esler 1993), the tumbleseeds that are not trapped are deleted from the model.

After dispersal, within-cell rates of germination and initial seedling survival are determined using the rainfall data. The dynamics for a single iteration (1 yr) proceed as follows: First, subsequent survival of seedlings within a cell is determined as a function of competition among surviving seedlings and by the current state of the cell and its neighbors. If there are seedlings of more than one species within a cell, survival first depends on the competitive hierarchy of the seedlings (Brownanthus ciliatus $>$ Galenia fruticosa $>$ Ruschia spinosa and O. sinuatum $>$ $P$. pallens) and then on root competition with adjacent adult shrubs (gap size). At most, one seedling is allowed to survive within a cell. After seedling survival is determined, time and weather effects on plant growth and the attainment of reproductive maturity are considered. Mortality of established, nonsenescent plants is low and caused mainly by disturbance. Therefore, nondisturbance mortality is only modeled after the plants have attained $80 \%$ of their expected life spans (B. ciliatus, $10 \mathrm{yr}$; G. fruticosa, $30 \mathrm{yr}$; R. spinosa, $25 \mathrm{yr}$; P. pallens, $70 \mathrm{yr}$; and O. sinuatum, $50 \mathrm{yr}$ ). Thereafter, the probability of mortality increases exponentially.

Disturbances that have an impact on a cell cause the mortality of adult plants and all seedlings within the disturbed cell. Plants that have not attained more than $60 \%$ of their maximal size are uprooted, and a pit lasting for $1 \mathrm{yr}$ is created. Larger plants are killed but not totally uprooted. In this case, the dead plant decays exponentially within the next $10 \mathrm{yr}$. After these steps are completed, the cycle for $1 \mathrm{yr}$ is finished and the simulation of the next year begins.

\section{Simulation Experiments}

We conducted a series of model runs, simulating the spatial and temporal dynamics of the plant community for $N=2,000 \mathrm{yr}$. The landscape-level rate of disturbance was held fixed within each of 16 model runs, but a broad range of values was tested among model runs. The disturbance regime was random in space and time, and individual disturbances were always square in shape and had a size of four cells $\left(\approx 0.44 \mathrm{~m}^{2}\right)$. For each model run, we produced a fixed number of disturbances each year 
and placed them at random over the simulation grid. The resulting average landscape-level disturbance rates varied (between model runs) from $0 \%$ to $5 \%$ of the area disturbed per year. Because the typical timescale of the system is decades rather than years (Wiegand et al. 1995; Wiegand and Milton 1996), we characterize the disturbance regime through the (mean) proportion of the total area disturbed over a 10-yr period (accumulated disturbance rate), rather than through the annual disturbance rate. The accumulated disturbance rates $d$ of the 16 model runs were $0.0,0.05,0.09,0.13,0.18,0.21,0.26$, $0.28,0.31,0.34,0.37,0.40,0.43,0.46,0.48$, and 0.51 .

The initial plant distribution was generated by simulating community dynamics for $93 \mathrm{yr}$, employing the empirical Prince Albert rainfall data (Wiegand and Milton 1996). During this procedure, we calibrated the initial plant densities so that the plant distribution at the ninety-third time step corresponded to the relative abundances observed at the Tierberg site (Milton and Dean 1990). The resulting initial plant distribution contained a history of establishment, competition, and dispersal events, producing a "realistic" age structure and a "realistic" spatial pattern for subsequent analysis. For the $2,000 \mathrm{yr}$ of a model run, stochastic rainfall data were produced by the rainfall simulation program GENRAIN (Zucchini et al. 1992), as briefly described above.

We based a majority of our analyses on model output for individual model runs conducted at each disturbance rate. However, this was only done after comparative analyses of 15 replicate model runs at several disturbance rates (see below), which clearly demonstrated the strong ergodic behavior of the model (i.e., although the exact locations of individual plants differed, the statistical properties were essentially the same for model runs conducted at the same disturbance rate). As a consequence of the ergodic behavior of the model, a sufficient understanding of the general relationship between model structure and pattern formation can be developed through the analysis of individual model runs at each disturbance rate.

\section{Pattern Analysis Techniques}

Spatiotemporal patterns of ecological variables are of particular interest to ecologists because they can reveal information about stand history, population dynamics, and competitive interactions (Haase 1995). These patterns generally arise from spatial and/or temporal correlation in ecological processes operating at different scales. Of major importance are so-called second-order effects, effects that result from local interactions and produce patterns associated with the covariance structure among ecological units (e.g., among individual plants or plant assemblages). In the present study, we can examine second-order effects in detail, since our model produces maps containing the location of every individual plant during each simulation time step (year). We can also determine the relationship between patterns produced by the model and the underlying community dynamics.

The techniques of statistical pattern analysis provide a variety of methods that allow the investigation of secondorder effects in space and time, including autocorrelation and cross-correlation analysis, which can be used in analyzing temporal and spatial patterns of continuously distributed variables (see, e.g., Diggle 1990); nearest neighbor analyses (Upton and Fingleton 1985), which can be used to characterize the distribution of individual points as being random, clustered, or evenly (hyper-) dispersed, without accounting for scale; and more sophisticated, reduced, second-order moment measures that do account for changes in the pattern of points across a range of scales. The second-order moment measures include Ripley's $K$-function analysis, for analyzing a single set of points (Ripley 1981; Bailey and Gatrell 1995), and bivariate $K$-function analysis (Diggle 1983; Upton and Fingleton 1985) or space-time clustering analysis (Diggle et al. 1991) for analyzing multivariate point patterns. These techniques can be used to detect scale-dependent nonrandom pattern in the covariance structure of a point pattern.

We focused our analyses in the present study on colonizer and successor life-history types rather than on individual species, since our basic interest was in studying the effects of local interactions among plant species belonging to the two functional groups found in the Karoo shrubland. We will use two general types of pattern analysis to study how disturbance may change the local interactions between successor and colonizer species in the semiarid Karoo shrubland. First, we will analyze the time series of landscape-level species abundances using autocorrelation and cross-correlation analysis. Second, we will analyze spatial and spatiotemporal patterns of the distributions of individual colonizer and successor plants, using univariate and multivariate $K$-function analysis.

\section{Auto- and Cross-Correlation Analysis}

We used autocorrelation and cross-correlation analysis to examine the average degree of temporal coherence in the landscape-level distribution of colonizer and successor species as a function of the temporal lag $k$ (or time) separating sample points. For each time step $t$, we calculated the total number of colonizer plants $s_{\mathrm{c}}(t)$ and the total number of successor plants $s_{s}(t)$ in the landscape. We then estimated the autocorrelation relationships $\rho\left(s_{i}, k\right)$ for each life-history type and the cross-correlation $\gamma\left(s_{1}\right.$, 

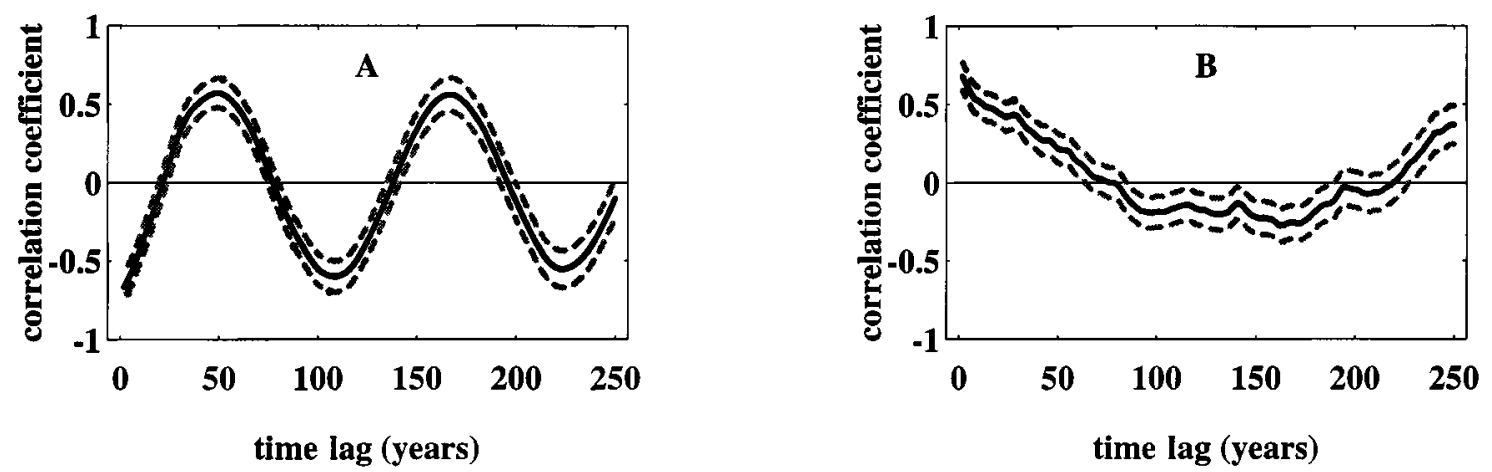

Figure 2: Mean cross-correlation (solid lines) and 95\% confidence envelopes (dashed lines) for 15 replicate model runs at the extreme disturbance rates of $d=0.00(A)$ and $d=0.51(B)$. The $95 \%$ confidence interval was calculated using the theoretical relationship given in equation (1). These analyses were conducted on model runs of $N=500 \mathrm{yr}$, which utilized the same random rainfall data set and initial plant distribution. Variability among runs comes through the action of a considerable number of random variables (e.g., seed dispersal, mortality, disturbance) that determine the location of individual plants.

$\left.\boldsymbol{s}_{2}, k\right)$ between types, with $\boldsymbol{s}_{1}$ and $\boldsymbol{s}_{2}$ representing the vector of values $\boldsymbol{s}_{1}(t)$ and $\boldsymbol{s}_{2}(t)$ for life-history types $i=1$ and 2, respectively, with $t=1-2,000$. (Standard formulas for calculating $\rho\left(s_{i}, k\right)$ and $\gamma\left(s_{1}, s_{2}, k\right)$ from time-series data can be found in any textbook covering time-series analysis; see, e.g., Chatfield 1984.) Assuming that the values in $s_{1}$ and $s_{2}$ are normally distributed, the $95 \%$ confidence envelope $\left(\gamma\left(s_{1}, s_{2}, k\right) \pm \delta(k)\right)$ for the autocorrelation or cross-correlation function can be calculated using the following relationship:

$$
\delta(k)=\frac{z_{a}}{\sqrt{N-k}}
$$

and $z_{\alpha}=1.96$ for a significance level of .05, if $N$ (the total number of sample points) is relatively large (Chatfield 1984; Bronstein and Semendjajew 1991).

A preliminary analysis of cross-correlation relationships among 15 replicate model runs at two disturbance rates (fig. 2) clearly shows that the general patterns produced by the model are not affected by the considerable number of random variables (e.g., seed dispersal, mortality, disturbance) involved in determining the location of individual plants. The reason for this lies in the strong synchronizing effect of rainfall events, the dynamic inertia of the system (Wiegand et al. 1995), and the sufficiently large grid size. Because of this result, we will only consider individual model runs at each disturbance rate in the remainder of this article.

\section{K-Function Analysis}

We used Ripley's $K$-function analysis to examine spatiotemporal patterns in the distributions of colonizer and successor species across a range of spatial scales $h$. All of the analyses were based on the general univariate $K$ function $K_{11}(h)$ and its bivariate extension $K_{12}(h)$. Generally,
$K$ functions are rescaled to $L$ functions. This transformation stabilizes the variance, is simpler to plot, and makes the expected values of $L_{12}(h)$ independent of the scale $h$ (see Haase 1995 for a discussion of $K(t)$ transformations). In the univariate case, $L_{11}(h)$ is used to characterize the degree of clustering or hyperdispersion of a set of points $l^{1}$ relative to a randomly distributed set of the same number of points. For the bivariate case, $L_{12}(h)$ is used to characterize the degree of clustering or hyperdispersion of a set of points $l^{2}$ (pattern 2) with respect to a second set of points $l^{1}$ (pattern 1; Ripley 1976, 1981; Cressie 1991; Bailey and Gatrell 1995). In both cases, the scale $h$ corresponds to a circular area of radius $h$ around individual points of pattern 1 . We use the standard formulas given in Bailey and Gatrell (1995, pp. 120, 121) for the calculation of $L_{11}(h)$ and $L_{12}(h)$.

In the univariate case, if the distributional pattern of $l^{1}$ is spatially random at scale $h$, then the expected value of $L_{11}(h)$ is 0 , otherwise $L_{11}(h)<0$ for an evenly distributed pattern at scale $h$ and $L_{11}(h)>0$ if it is clustered. The same is true for the bivariate case, if a set of points $l^{2}$ is hyperdispersed with respect to a second set of points $l^{1}$ then $L_{12}(h)<0$, whereas $L_{12}(h)>0$ under clustering. In order to interpret the significance of $L_{11}(h)$ and $L_{12}(h)$ across a range of scales, it is necessary to be able to test for significant departures from the null hypothesis of independence. This is generally done through the estimation of confidence intervals using Monte Carlo simulations (Ripley 1981; Cressie 1991; Bailey and Gatrell 1995). For the analysis of univariate and bivariate spatial point patterns produced by our model, we estimated 95\% confidence intervals around the expected value of $L_{11}(h)=0$ or $L_{12}(h)=0$ and used these to test for significant departures from a random pattern. The confidence intervals were constructed by randomizing the positions of $N_{1}$ points (univariate case) or $N_{1}$ and $N_{2}$ points 
(bivariate case) 19 times within the model landscape (Haase 1995). ( $N_{1}$ and $N_{2}$ were equal to the number of points in model patterns 1 and 2, respectively.) We then determined values of $L_{11}(h)$ or $L_{12}(h)$ for the randomized patterns. Significant clustering in the model pattern was indicated for values of $L_{11}(h)$ or $L_{12}(h)$ that were greater than the maximum $L_{11}(h)$ or $L_{12}(h)$ obtained through the randomization procedure, and significant repulsion was indicated by $L_{11}(h)$ or $L_{12}(h)$ values that were less than the smallest value obtained through randomization (see Haase 1995).

\section{Space-Time Clustering}

In analyzing vegetation dynamics of the colonizer and successor species in the Karoo shrubland, we were interested in how spatial pattern changes over time-that is, whether events cluster in space over time. Despite the general interest of ecologists in studying dynamic processes, space-time clustering techniques have been used so far almost exclusively in an epidemiological context (Diggle et al. 1991). However, patterns of space-time clustering are of particular interest in the Karoo system, where cyclic succession produces strong time lags in the establishment of successor species dependent on the earlier establishment by colonizer species, at least in the absence of disturbance. These relationships may also have a strong spatial component. In order to assess these relationships, we regarded vegetation maps at different times as being different patterns and analyzed these spatiotemporal patterns using $L_{12}(h)$. Ninety-five percent confidence intervals for these tests were calculated in the same way as in the spatial pattern analyses, except that only the pattern occurring later in time was randomized. We held the earlier pattern fixed, as our null hypothesis was that the later patterns did not depend on the spatial structure of the earlier pattern.

Results

\section{Temporal Pattern Analysis}

The temporal dynamics of the Karoo shrubland model were quite sensitive to changes in disturbance rate (fig. 3). Without disturbance (fig. 3A), all five species could coexist for the entire simulation period. Nevertheless, community dynamics did not reach a state of equilibrium. Instead, the dynamics were characterized by a mixture of large cycles caused by cyclic succession and epi-

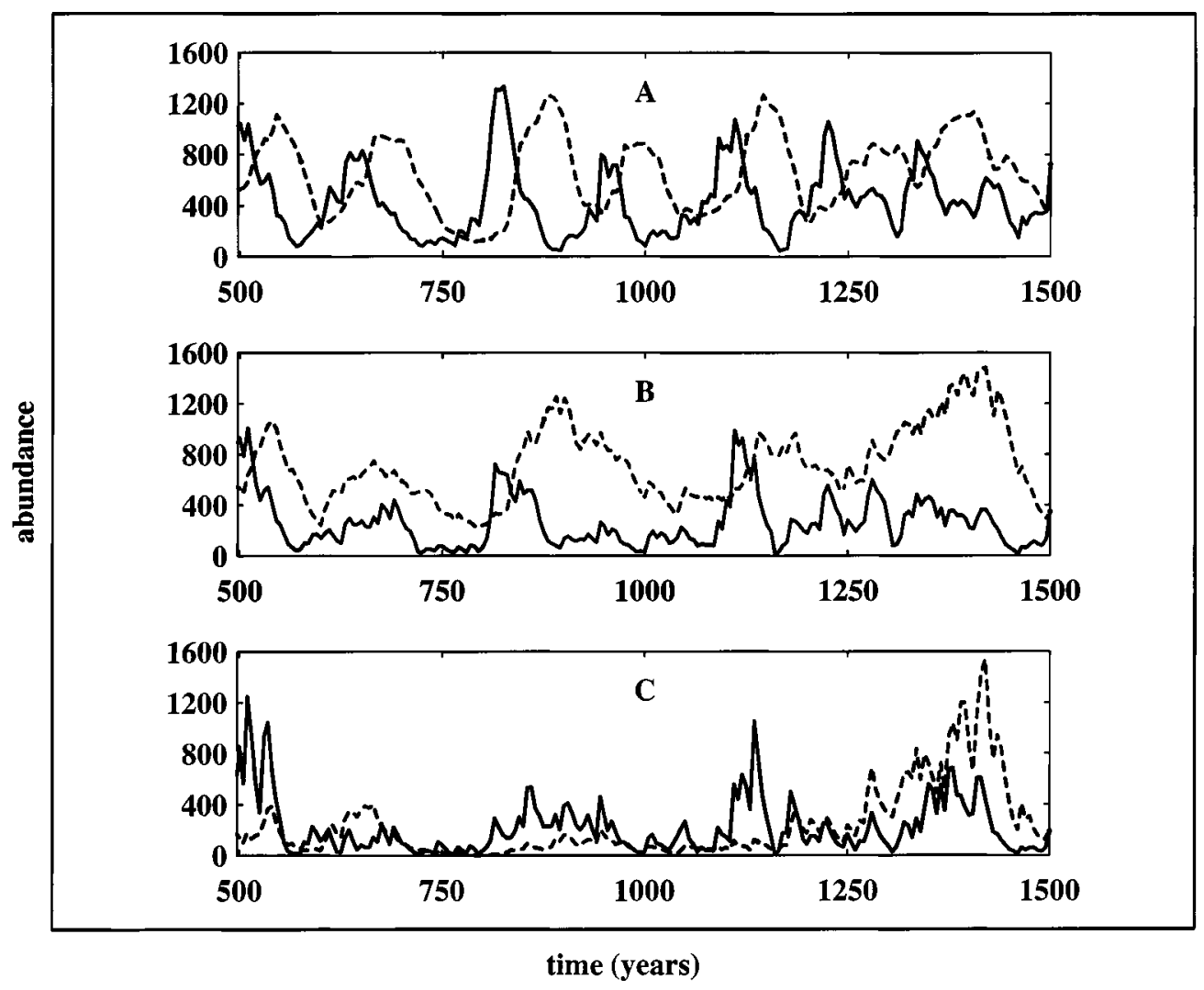

Figure 3: Time series showing the number of colonizer (solid line) and successor plants (dashed line) in model runs with different disturbance rates. The disturbance rates were: $d=0.00(A) ; d=0.18(B) ; d=0.51(C)$. 


\section{The American Naturalist}

sodic event-driven behavior, with quasi-stable periods being interrupted by big establishment or mortality events (Wiegand et al. 1995). Bigger establishment events occur in the model only if a high number of establishment sites are available and if rainfall conditions are extraordinarily favorable (Wiegand et al. 1995). Because potential establishment events are not synchronous for all species (seed production, germination, and seedling survival depend on different rainfall thresholds), one species can sometimes dominate a functional group for several decades, while the other species remain at low abundance. This happens when one species accidentally has an advantage over the other species (e.g., through an earlier establishment event, more establishment events, or higher abundance during an establishment event).

At intermediate disturbance rates (fig. $3 B$ ), successor species are freed from the pattern of cyclic succession (open $\rightarrow$ colonizer plant $\rightarrow$ successor plant $\rightarrow$ open) that dominates when disturbance rates are low, because disturbance (pits and dead plants) provides additional establishment sites (see also fig. 1). Without disturbanceinduced mortality, growth of successor seedlings is often suppressed for several years until their host plant becomes senescent, and establishment of seedlings may be considerably time delayed from the years where rainfall conditions permit seed production, germination, and postgermination survival.

At high disturbance rates (fig. 3C), disturbanceinduced mortality strongly limits the abundance of species. However, outbreaks of plant establishment can occur during periods when there is an aggregation of establishment events due to favorable environmental conditions.

The impact of disturbance on the pattern of cyclic succession can be more fully understood by examining the temporal autocorrelation and cross-correlation relationships for the colonizer and successor species (figs. 4, 5). It is quite clear from the cross-correlation relationship at time-lag zero that disturbance breaks the pattern of cyclic succession between colonizer and successor species (fig. 4). Without disturbance, the abundance of colonizer and successor plants is highly negatively correlated. The negative correlation disappears with increasing disturbance rate and changes to a significant, positive correlation at a disturbance rate of about $16 \%$ of the cells in the landscape being disturbed during a $10-y r$ period. At this point, establishment events have become synchronous for both functional groups. In this case, the probability $P$ for the colonizer species escaping disturbance-induced mortality $\left[P=(1-m)^{L}\right]$ is 0.85 for Brownanthus ciliatus, 0.61 for Galenia fruticosa, and 0.67 for Ruschia spinosa, assuming mean life spans $L$ of 10,30 , and $25 \mathrm{yr}$, respectively, and an annual disturbance rate of $m=0.016$. Thus, the change from negative correlation to positive

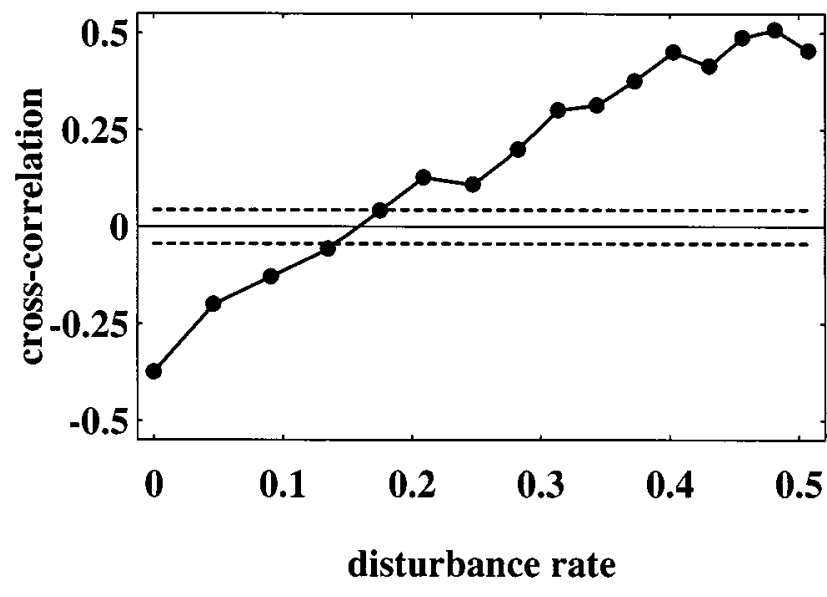

Figure 4: The temporal cross-correlation at lag 0 between the abundance of colonizer and successor species as a function of disturbance rate. Dashed lines: $95 \%$ confidence envelops for no significant cross-correlation.

correlation occurs if $60 \%-70 \%$ of all cyclic successions are disrupted by disturbance. This result confirms an earlier expectation that community dynamics might change qualitatively if the local pattern of cyclic succession was interrupted in the majority of all cases (Wiegand et al. 1997).

Without disturbance, community dynamics are strongly dominated by the pattern of cyclic succession, leading to a marked oscillatory behavior in the temporal autocorrelation and cross-correlation relationships for the two functional groups (fig. 5A). The autocorrelation relationships indicate that the population sizes of the functional groups have a periodic structure, with cycles of approximately 120-140 yr. The cycles of these two functional groups, however, are out of phase by about 50 or $60 \mathrm{yr}$, as can be seen in the corresponding crosscorrelation relationship (fig. 5A). This lag effect is caused by the demographic inertia built into the process of cyclic succession: a plant population requires a rare event for establishment to occur, but once this happens, the resulting cohort persists for a long time. Creation of abundant establishment sites for the other species can only occur if the plants of the currently established cohort die simultaneously. As a consequence, the scale of the phase shift between functional groups is controlled by the mean life spans of the longer-lived successor species Osteospermum sinuatum (50 yr) and Pteronia pallens (70 yr).

Significant cyclic relationships exist for lags of up to $250 \mathrm{yr}$ if the disturbance rate remains below approximately $18 \%$ (fig. 6). This result is surprising since the underlying rainfall data are random in time. As a consequence, we expected that the occurrence (or nonoccurrence) of rare establishment events would desynchronize the pattern of cyclic succession at lags greater than one cycle. At intermediate disturbance rates, the periodicity in 


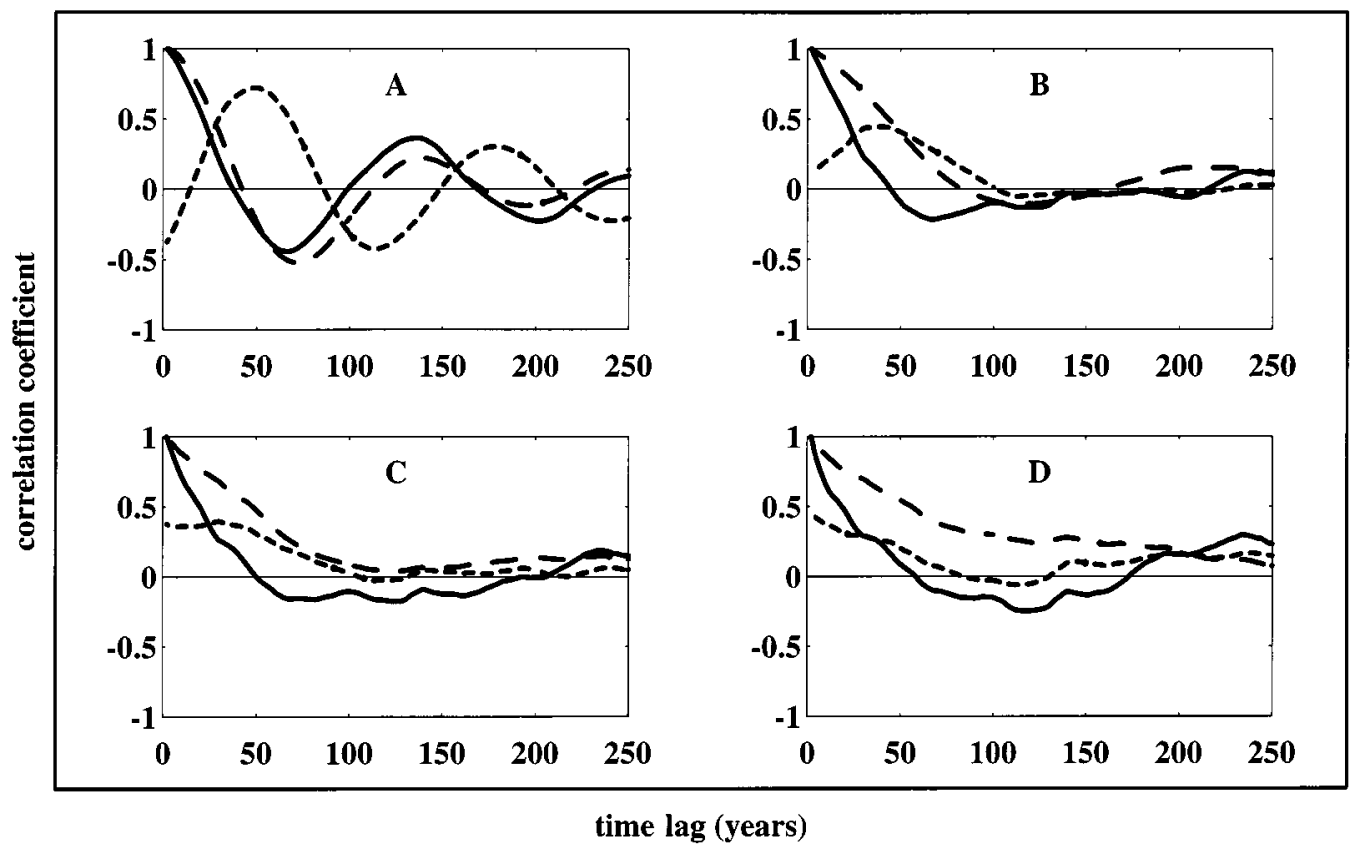

Figure 5: Temporal autocorrelation of the abundance of colonizer (solid line) and successor plants (long-dashed line) and the crosscorrelation (short-dashed line) between abundances of colonizer and successor plants at four different disturbance rates as a function of temporal lag. The disturbance rates: $d=0.00(A) ; d=0.21(B) ; d=0.37(C) ; d=0.51(D)$.

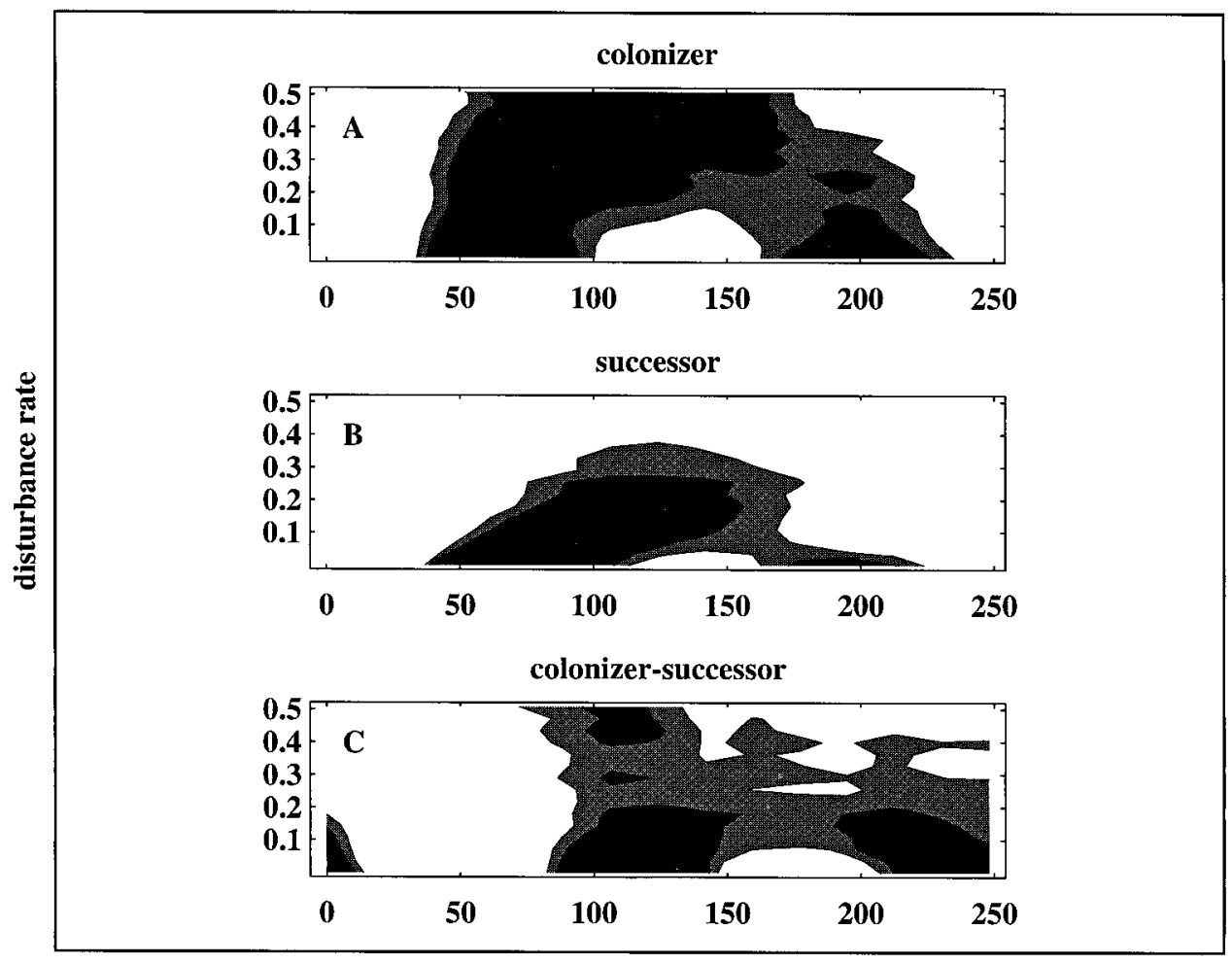

time-lag (years)

Figure 6: Autocorrelation and cross-correlation relationships of colonizer and successor plants as a function of time lag and disturbance rate. White: significant positive correlation; black: significant negative correlation; and, gray: no significant correlation. 


\section{The American Naturalist}

the autocorrelation and cross-correlation relationships disappears completely (fig. $5 B, C$ ). Instead, the autocorrelation decays to 0 with an approximate 50 -yr time lag for the colonizer species and at a 70-100-yr time lag for the successor species. The difference between these two functional groups is due primarily to differences in average life span. Visible evidence of the pattern of cyclic succession still exists in the crosscorrelation relationship for disturbance rates as high as 0.21 (indicated by a peak at lag 40 in fig. $5 B$ for the cross-correlation relationship), although the negative correlation at shorter time lags is no longer significant (figs. 4, 6). All evidence of the pattern of cyclic succession, however, is gone from the cross-correlation relationship for disturbance rates of 0.31 and above (figs. 4-6).

At the highest disturbance rates $(d>\approx 0.4)$, the successor species are positively correlated across all time lags examined (0-250). This is the result of long temporal trends in abundance due to stochastic environmental factors and underlying demographic momentum produced by the abundant production of establishment sites through disturbance (figs. 3, 5D, 6). Colonizer species, on the other hand, exhibit very little response to increasing disturbance, once the pattern of cyclic succession is broken, since disturbance events do not significantly improve their chances of successful establishment (figs. $5,6)$.

\section{Univariate Analysis of Spatial Point Patterns}

Although the time-series analysis was quite revealing, a deeper understanding of the interplay between colonizer and successor species can be gained through a careful analysis of the spatial relationships that develop over time, using Ripley's $K$ function. We will focus first on the case of no disturbance, since this is where the pattern of cyclic succession is most distinct. We will then briefly contrast this to an analysis of a simulation including disturbance. We will limit these analyses primarily to time steps 750-950, as this encompasses a complete cycle in the dynamics of the system.

A close look at how spatial pattern changes over the course of time provides more insight into the relationship between pattern formation and the process of cyclic succession than would otherwise be possible (fig. 7). Several abrupt changes in the pattern of species distributions can be seen over time, corresponding to different states in the process. Changes in the colonizer pattern can be traced to a fundamental shift in the process of recruitment as population size increases. Initial establishment can be traced to seed dispersing from a few remaining randomly scattered colonizers $(t=750$, fig. $3 A)$. Once the first plants become established, they act as foci for lo- cal recruitment, as space is made available through the death of senescent successor plants and suitable environmental conditions for establishment occur. These form "condensation hot spots" for the eventual spread of the colonizer species within the system. (The rate of spread is controlled by the limited dispersal distances of colonizer seeds, which move, at most, eight cells in linear distance from the parent plant). Because of the condensation effect, space is gradually filled by colonizer plants in increasingly large clusters (fig. 7A). Eventually, during a major recruitment event like the one between time steps 798 and 810 (cf. figs. $3 A$ and $7 A$ ), establishing plants fill most of the available space in the system. This leads to a rapid shift toward an even pattern across a broad range of scales. Eventually, the colonizers begin to die and the pattern shifts gradually from even, back to random $(810<t<890)$. Clustering begins to be seen again during the next recruitment event $(t>890)$.

The change in pattern observed for successor species during this same time period was different because of the dependence of the successors on the colonizers. Unlike the colonizer species, the successor species showed regular or random distributions across most scales (fig. 7C). This was due to the fact that the successor plants replaced dying colonizer species and "copied" their even spatial pattern during periods suitable for establishment. The lack of clustering observed for the successor species was also due, in part, to their relatively long dispersal distances, which allowed them to spread rapidly through the system.

Since the pattern-forming process under conditions of no disturbance was primarily related to the underlying process of cyclic succession, we examined pattern formation under increasing disturbance rates to more thoroughly understand the ecological processes behind the observed breakdown in the pattern of cyclic succession. We present the results here for a representative run, which had an average disturbance rate of $d=0.18$ over a 10 -yr period. This disturbance rate was slightly above the rate at which there was a switch from negative correlation at lag 0 to positive correlation (fig. 4). It was also outside the range of disturbances where cyclic succession dominated the dynamics of the system (figs. 5, 6).

In this example, the spatial patterning of colonizer species did not change qualitatively with the introduction of disturbance into the system (fig. $7 A, B$ ), since two basic processes remained unchanged: the main aggregating mechanism of short-distance seed dispersal and the reliance on sufficient rainfall for establishment success. There was, however, a decrease in the maximum abundance observed for the colonizers due to the occupation of more suitable sites by successors (cf. fig. $3 A, B$ ). In contrast, successor species were freed from the pattern of 


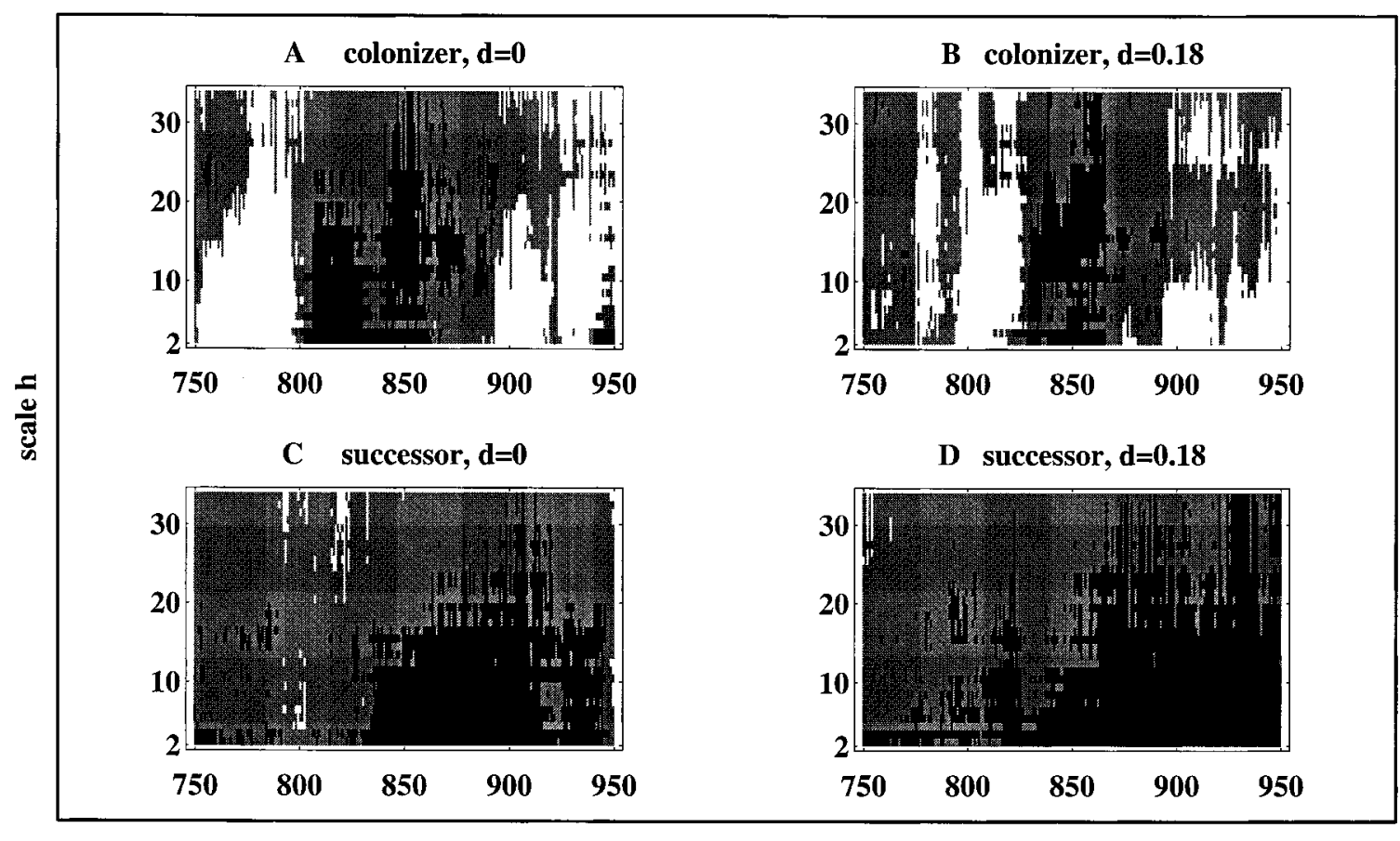

time (years)

Figure 7: Univariate $L$ analysis as a function of time and scale for the spatial distribution of colonizer plants $(A, B)$ and successor plants $(C, D)$. The figures on the left $(A, C)$ are for a model run without disturbance $(d=0)$ and those on the right $(B, D)$ are for a run with a disturbance rate of $d=0.18$. For the $L$ analyses, white cells indicate significant clustering in the point-pattern, black cells indicate significant hyperdispersion, and gray cells indicate no significant departure from random. The corresponding time series are shown in figure 3.

cyclic succession and were able to establish at any time that environmental conditions were suitable. This occurred since there was always an abundance of suitable establishment sites due to the widespread production of pits and dead stems through disturbance. And, although the general pattern seen in the undisturbed case-a period of randomly distributed plants at low abundance leading to evenly distributed plants-was also found with disturbance, it was to some extent uncoupled from the prior development of an even pattern in the colonizer species (e.g., $825<t<875$, fig. $7 B, D$ ).

\section{Bivariate Analysis of Spatial Point Patterns}

In the previous section, we analyzed whether the spatial pattern of colonizer and successor plants-each taken separately-exhibited significant clustering or regularity. We found evidence that, in the absence of disturbance, local interactions between individual plants played an important role in the process of spatial pattern evolution within each life-history type but that there was little change in these relationships in a model run incorporating an intermediate level of disturbance. The latter result was unexpected, particularly given the strong response to disturbance observed in the time-series analyses. Further insight may be gained by looking at the relationship in spatial patterns between life-history types using bivariate $L$ analysis, that is, $L_{12}(h)$. With this in mind, we compared $L_{12}(h)$ values for the undisturbed case with values for a model run with an average disturbance rate of $d=$ 0.18 , as in the previous analysis.

The bivariate point-pattern analysis of the undisturbed shrubland illustrates the process of cyclic succession quite clearly (fig. 8A). In general, the relationship between colonizer and successor species exhibits dynamic nonrandom behavior in the development of pattern, indicating strong spatial interactions. The small-scale $(h<5)$ processes were generally indicative of patterns of repulsion between the two groups of species, interspersed with brief periods of random intermingling or attraction. The latter periods occurred primarily during times when there was a shift in dominance from one group of species to the other (cf. time series in fig. $3 A$ and pattern analysis in fig. $8 A$ ). Patterns at intermediate scales $(20>h>5)$ were indicative of the spacing among colonizer and successor species over broader areas and amplified the pat- 


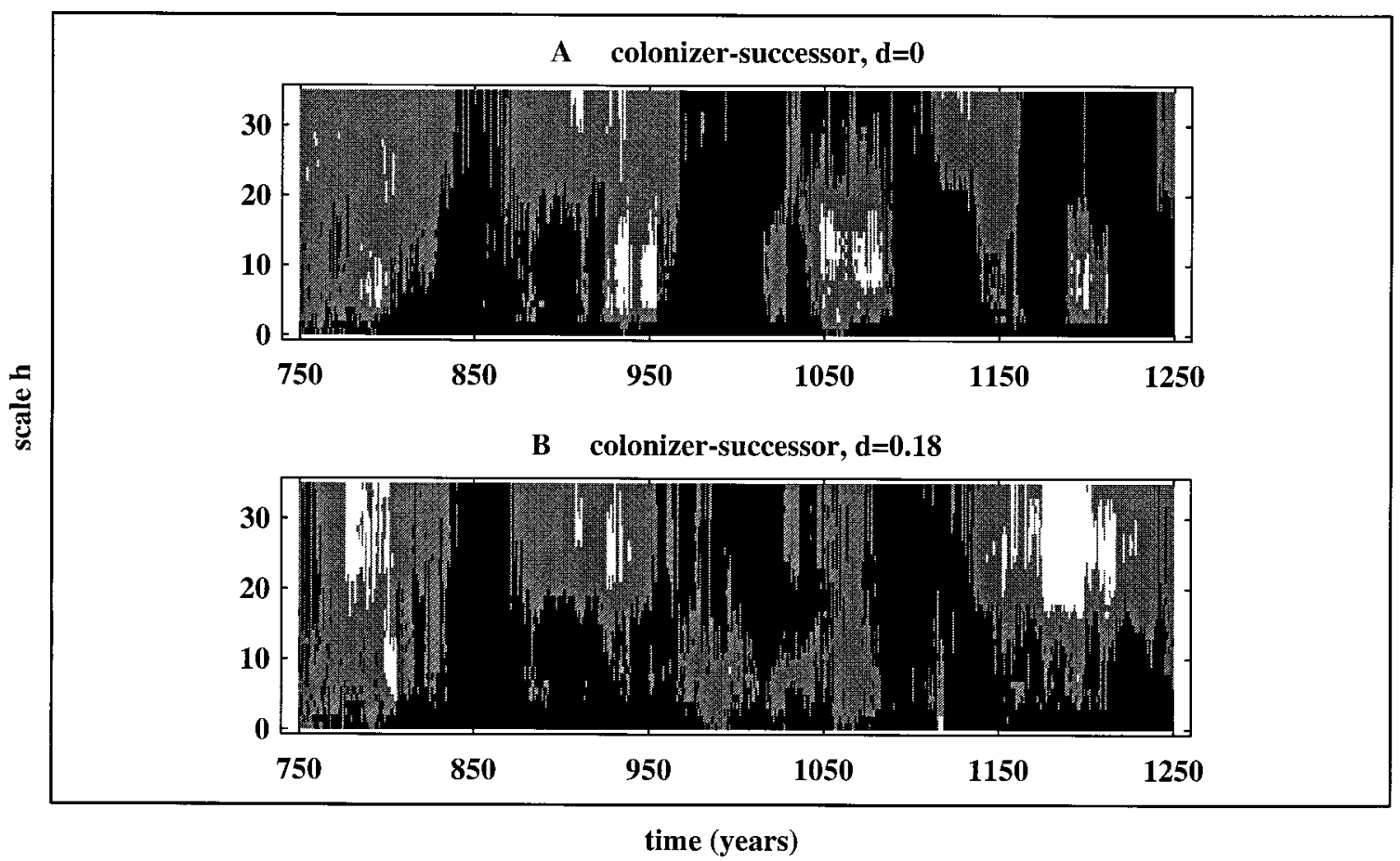

Figure 8: Bivariate $L$ analysis of the spatial distribution of colonizer plants and successor plants between time steps 750 and 1,250 for a model run without disturbance $(A)$ and for a run with a disturbance rate of $d=0.18(B)$. For the bivariate $L$ analyses, white cells indicate significant attraction between the two types of plant species, black cells indicate significant repulsion, and gray cells indicate no significant spatial relationship. The corresponding time series are shown in figure 3.

tern at the smaller scales, showing a greater tendency toward clustering during the changeover in dominance from one group of species to the next. These patterns were quite interesting as they exhibited a cyclic alternation between periods of repulsion and periods of spatial independence or attraction (fig. 8A).

The periodic change between attraction and repulsion at intermediate scales for colonizer and successor species in the undisturbed case was caused by the "memory" imbedded in the system through the process of cyclic succession. A strong tendency toward repulsion was observed during phases of rapid "recolonization" by the colonizer species into areas of decline for the successor species (e.g., following from years 800, 955, 1,070; see fig. $3 A)$. During these periods of time, the colonizer plants formed dense clusters around invading individuals in "condensation hot spots" and the remaining successor plants were generally located outside of these clusters, resulting in a pattern of repulsion moving rapidly from the smaller scales to the broader scales. A breakdown in the pattern of broad-scale repulsion occurred either during the initial invasion of clusters of colonizer plants by successor plants (a weak tendency seen around years 795, 950, and 1,060) or when big gaps of unoccupied cells were produced by a rapid decline in the population of successor species, prior to invasion by colonizers (a stronger tendency seen around years 750, 940, 1,050, and $1,190)$. In the latter case, colonizer and successor plants were mixed together within shrub-occupied areas, and the resulting pattern of general attraction was due more to the occurrence of prominent gaps in the pattern than it was to an affinity among species.

The most striking feature of the bivariate spatial pattern under conditions of no disturbance-the periodic change between attraction and repulsion at intermediate scales-completely disappeared with the introduction of an intermediate level of disturbance (fig. $8 B$ ). Instead, the pattern was either hyperdispersed or random, shifting between these two states in a somewhat irregular fashion. Disturbance acted to disrupt the local pattern of cyclic succession, which was replaced by a pattern more indicative of recruitment events produced by variable rainfall patterns, keyed to the demographic attributes of the distinct life-history types. In contrast, under disturbance there was a stronger pattern of alternating periods of attraction and repulsion between colonizer and successor species at the broader scales $(h>20)$ than was seen in the absence of disturbance. The cause of the latter result 
is not easy to determine from inspection of the raw data and a more thorough analysis will be required in the future to understand the root cause of this finding.

\section{Space-Time Clustering}

In an extension of the analysis in the previous section, we conducted a study of space-time clustering by analyzing more directly how spatial pattern at one time period depends on pattern during an earlier time period. We did this using bivariate $L$ analysis at a scale of $h=1$, essentially focusing on the relationship between the presence/ absence of colonizer plants in individual cells at time step 820 and the presence/absence of successor plants within the same cells during the next $200 \mathrm{yr}$ (fig. 9). This is analogous to the cross-correlation analysis of the time series presented earlier, but instead of focusing on the process at the landscape scale, we now focused on the process at the smallest scale that occurred in our model. We chose to examine the relationship between colonizers at time step 820 and successors during subsequent time steps, as colonizer plants were at high abundance at time step 820 and replacement by successor species followed soon after. Initially, the relationship between colonizers and successors was characterized by strong repulsion, which is not surprising since successors cannot occupy the same cell as a colonizer during the same time period. During the first $30 \mathrm{yr}$ of the analyzed time span (corresponding approximately to the life span of the colonizer species), colonizer plants were replaced by successor plants and the relationship changed to one of significant attraction. After $70 \mathrm{yr}$, the relationship changed again, becoming essentially random for $t>920$. This occurred because successor plants died and colonizer plants once again established in the newly created gaps.

\section{Discussion}

There is wide-ranging interest in understanding spatial interactions and their impact on ecological systems, and there are currently several approaches being employed to study these relationships. A common goal is to understand how local interactions at one level of biological organization influence phenomena at higher levels. One popular approach employs the use of spatially explicit simulation models (e.g., Hassell et al. 1991; Silvertown et al. 1992; Colasanti and Grime 1993; Wiegand et al. 1995; Jeltsch et al. 1996; Moloney and Levin 1996). For example, the model presented here offers the potential for exploring the long-term vegetation dynamics of a semiarid plant community by extrapolating from the behavior of individual plants to long-term community-level dynamics. We used our model to explore the effects of introducing disturbance into a system dominated, in the absence of disturbance, by a pattern of cyclic succession. This allowed us to conduct a controlled experimental manipulation over a wide array of disturbance regimes and over long time spans-manipulations that would be impossible to perform in the field. Another advantage of the modeling approach is that we have complete knowledge of the temporal and spatial distributions of individual plants in the model system. With this information we can examine the relationship between pattern evolution and the underlying ecological dynamics. This can provide some very useful insights into the spatial and temporal relationships we might expect to see under different eco-

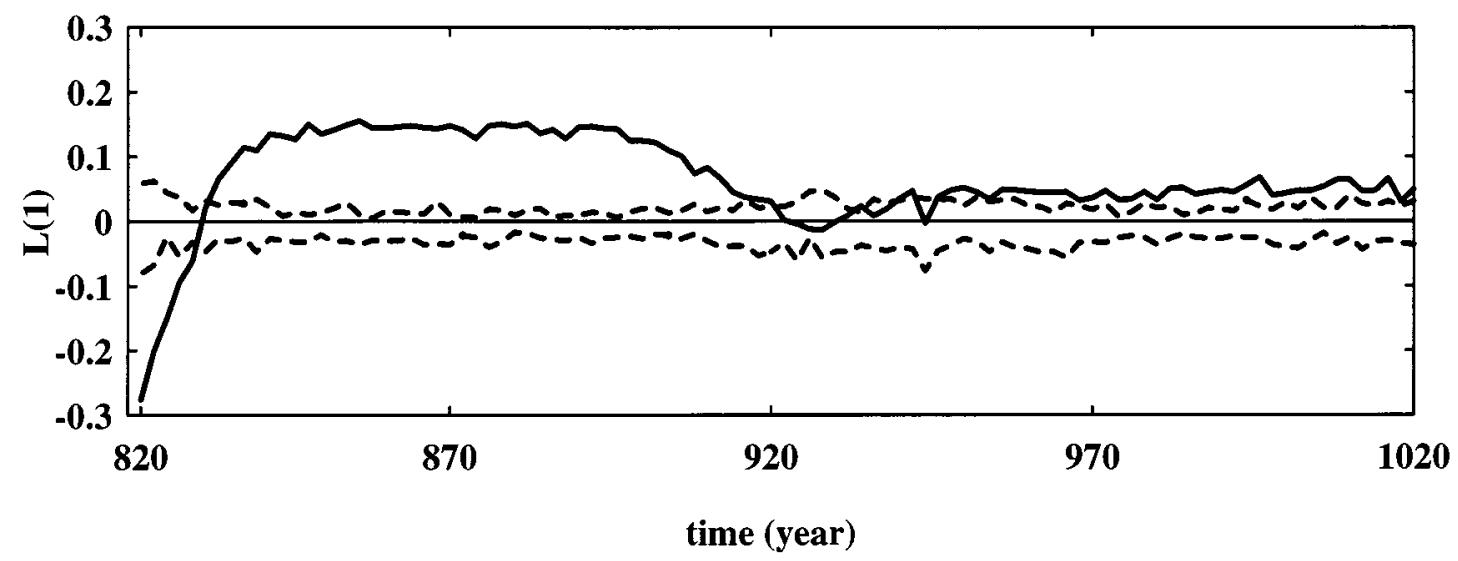

Figure 9: Space-time clustering, as depicted through bivariate $L$ analysis (solid line), with corresponding 95\% confidence envelope (dashed lines). The $L$ analysis shows the relationship between the presence/absence of colonizer plants in individual cells at time step 820 and the presence/absence of successor plants within the same cells at time steps from 820 to 1,020 for a model run without disturbance. 


\section{The American Naturalist}

logical conditions in the field. It also suggests possible tests of the predictions made by the model. For example, do we find that spatial relationships between colonizer and successor species are expressed at broader scales in areas of the Karoo in which disturbances have a heavier impact than in areas with lower disturbances rates, as demonstrated by the model?

Curiously, very few studies using spatially explicit simulation models have analyzed pattern evolution explicitly; instead, they have focused on more general outcomes, such as the pattern of landscape-level species abundance and diversity produced under varying ecological conditions. In this article, we find that the precise analysis of spatiotemporal patterns, using techniques such as autocorrelograms, cross-correlograms, and Ripley's K-function analysis, may be particularly appropriate for studying the output of spatially explicit simulation models. A great deal of insight about the underlying relationships operating in the system may be gained in this way.

In our case, the goal of pattern analysis was to gain insight into the relationship between pattern and process in a semiarid shrub community and to understand how spatiotemporal pattern evolution may be changed by small-scale disturbances. Autocorrelation and crosscorrelation analysis of the time series of the abundance of colonizer and successor plant species revealed that overall community dynamics were strongly determined by the underlying pattern of cyclic succession when disturbance was absent. In this case, the correlograms of the abundance of colonizer and successor species showed a marked oscillatory behavior; the period was keyed to the typical timescales of the underlying community dynamics, was out of phase with the autocorrelation relationships due to the underlying relationships imposed by the process of cyclic succession, and persisted through at least two complete cycles with minimal decay in amplitude. Such a strong pattern persisting through more than one full successional cycle was surprising and could not have been assessed without the cross-correlation analysis of the model output. In fact, in an earlier more general analysis (Wiegand et al. 1995), we suspected that the random occurrence of bigger establishment events would desynchronize the pattern of cyclic succession to a far greater extent. Our initial understanding, however, may not have been entirely incorrect but was perhaps scale dependent. We did find, through the bivariate analysis of presence/absence relationships at the scale of individual cells, that the cyclic relationship between colonizer and successor species was a strong relationship, but it disappeared on the local scale after one successional cycle.

Our analysis outlines the importance of the indirect impact of disturbance on the spatial structure of successional systems. While the direct impact of disturbance- killing of plants and the opening up of space as new establishment sites — can be studied easily via more traditional analyses, an analysis of the indirect impact of disturbance requires a more sophisticated approach. We found that breaking up the pattern of cyclic succession through disturbance causes a subtle shift in the spatial relationships between functional groups and thus in the spatial organization of the system as a whole. However, we also found, in a very surprising result, that there was an apparent lack of an impact by disturbance on spatial patterning within individual life-history types (fig. 7). The reason for this can be traced to the manner in which these species spread through the system under suitable environmental conditions.

Although spatial patterning within life-history types appears to be insensitive to the introduction of disturbance, we found that the relationship between types was altered significantly. An alternating pattern of attraction and repulsion occurred at intermediate scales under conditions of no disturbance but shifted to broader scales under disturbance. This arose through a fundamental change in the relationship between life-history types, as establishment became less dependent on the local successional history of the system. Local patterns of cyclic succession break down, and pattern formation depends on interactions at a broader spatial scale and are driven to a large extent by the dispersal characteristics of the two types of species.

How do the findings here compare with what is known in general about the impact of increasing disturbance on pattern formation in ecological systems? Unfortunately, it is quite hard to answer this question, in general; only a few studies have specifically examined the relationship between disturbance and pattern evolution across a range of scales. Frelich and Reich (1995) examined the impact of changing fire frequencies on pattern formation in a boreal forest and found that the canopy consisted of a fine-grained patchwork of small monodominant stands at low disturbance rates (i.e., relatively low fire frequency) and was composed of large monodominant stands at high disturbance rates (i.e., relatively high fire frequency). Similarly, several studies have shown that the presence of a directional disturbance in subalpine fir forests (i.e., direct exposure to prevailing winds at high elevation) can cause a reorganization of the canopy structure, leading from a fine-grained pattern of randomly arranged, even-aged stands under low disturbance, to a more broad-scale, well-organized pattern of even-aged stands, so-called fir waves, under high disturbance (Moloney 1986; Iwasa et al. 1991; Sato and Iwasa 1993; Jeltsch and Wissel 1994). In a study utilizing a spatially explicit model of a grass-legume community, Schwinning and Parsons (1996) also found a shift from a 
fine-grained pattern of species distributions to one that was organized at a broader scale under increasing disturbance (see their fig. 5).

All of these examples, as well as the study presented here, suggest that an increase in the rate of disturbance in a system produces a shift in organization from a finegrained spatial pattern to one that is more coarse grained. Is this a general pattern or not? And, what are the long-term consequences? These are hard questions to answer. Clearly, more theoretical and empirical studies need to be conducted investigating the impact of disturbance on the spatial organization of ecological communities, particularly since human-generated disturbances continue to play an increasing role in structuring natural ecosystems.

\section{Acknowledgments}

Field studies by S.J.M. were supported by the Foundation for Research Development and the Department of Environmental Affairs and Tourism, South Africa, the Southern African Nature Foundation and the FitzPatrick Institute, University of Cape Town. Funding provided by the UFZ-Centre for Environmental Research, Leipzig, enabled all authors to travel between Germany, the United States, and South Africa for cooperative work. K.M. would like to thank David Oliver and Iowa State University for providing critical support that made completion of this project possible. We thank W. R. J. Dean, E. Gustafson, I. Hanski, F. Jeltsch, C. Wissel, and one anonymous reviewer for assistance during the development of ideas or for comments on drafts of this manuscript.

\section{Literature Cited}

Aguilera, M. O., and W. K. Lauenroth. 1995. Influence of gap disturbances and type of microsites on seedling establishment in Bouteloua gracilis. Journal of Ecology 83:87-97.

Armstrong, R. A. 1988. The effects of disturbance patch size on species coexistence. Journal of Theoretical Biology 133:169-184.

Bailey, T. C., and A. C. Gatrell. 1995. Interactive spatial data analysis. Longman Scientific and Technical, Harlow.

Bergelson, J., J. A. Newman, and E. M. Floresroux. 1993. Rates of weed spread in spatially heterogeneous environments. Ecology 74:999-1011.

Bradshaw, G. A., and T. A. Spies. 1992. Characterizing canopy gap structure in forests using wavelet analysis. Journal of Ecology 80:205-216.

Brokaw, N. V., and S. M. Scheiner. 1989. Species compo- sition in gaps and structure of a tropical forest. Ecology 70:538-541.

Bronstein, I. N., and K. A. Semendjajew. 1991. Taschenbuch der Mathematik, B.G. Teubner, Stuttgart.

Busing, R. 1995. Disturbance and the population dynamics of Liriodendron tulipifera: simulations with a spatial model of forest succession. Journal of Ecology 83: 45-53.

Casas, J. 1990. Multidimensional host distribution and nonrandom parasitism: a case study and a stochastic model. Ecology 71:1893-1903.

Chambers, J. C., J. A. MacMahon, and R. W. Brown. 1990. Alpine seedling establishment: the influence of disturbance type. Ecology 71:1323-1341.

Chatfield, C. 1984. The analysis of time series: an introduction. Chapman \& Hall, London.

Colasanti, R., and J. P. Grime. 1993. Resource dynamics and vegetation processes: a deterministic model using two-dimensional cellular automata. Functional Ecology 7:169-176.

Cressie, N. 1991. Statistics for spatial data. Wiley Interscience, New York.

Dean, W. R. J., and S. J. Milton. 1991. Disturbances in semi-arid shrubland and arid grassland in the Karoo, South Africa: mammal diggings as germination sites. African Journal of Ecology 29:11-16.

Dean, W. R. J., and R. I. Yeaton. 1992. The importance of harvester ant Messor capensis nest mounds as germination sites in the southern Karoo, South Africa. African Journal of Ecology 30:335-345.

Dean, W. R. J., S. J. Milton, P. G. Ryan, and C. L. Moloney. 1994. The role of disturbance in the establishment of indigenous and alien plants at Inaccessible and Nightingale Islands in the South Atlantic Ocean. Vegetatio 113:13-23.

Dessaint, F., R. Chadoeuf, and G. Barralis. 1991. Spatial pattern analysis of weed seeds in the cultivated soil seed bank. Journal of Applied Ecology 28:721-730.

Diggle, P. J. 1983. Statistical analysis of point patterns. Academic Press, London.

- 1990. Time series: a biostatistical introduction. Clarendon, Oxford.

Diggle, P. J., A. G. Chetwynd, R. Haggkvist, and S. Morris. 1991. Second-order analysis of space-time clustering. Technical Report MA91/62. Department of Mathematics, Lancaster University, Lancaster.

Esler, K. J. 1993. Vegetation patterns and plant reproductive processes in the succulent Karoo. Ph.D. thesis. University of Cape Town, Cape Town.

Frelich, L. E., and P. B. Reich. 1995. Spatial patterns and succession in a Minnesota Southern-boreal-forest. Ecological Monographs 65:325-346.

Gross, K. L., K. S. Pregitzer, and A. J. Burton. 1995. 
Spatial variation in nitrogen availability in three successional plant communities. Journal of Ecology 83: 357-368.

Haase, P. 1995. Spatial pattern analysis in ecology based on Ripley's $K$-function: introduction and methods of edge correction. Journal of Vegetation Science 6: $575-582$.

Hassell, M. P., H. N. Comins, and R. M. May. 1991. Spatial structure and chaos in insect population dynamics. Nature (London) 353:255-258.

Hobbs, R. J., and H. A. Mooney. 1985. Community and population dynamics of serpentine grassland annuals in relation to gopher disturbance. Oecologia (Berlin) 67:342-351.

Huston, M. A. 1979. A general hypothesis of species diversity. American Naturalist 113:81-101.

Iwasa, Y., K. Sato, and S. Nakashima. 1991. Dynamic modeling of wave regeneration (Shimigare) in subalpine Abies forest. Journal of Theoretical Biology 152: 143-158.

Jeltsch, F., and C. Wissel. 1994. Modelling dieback phenomena in natural forests. Ecological Modelling, 75/ 76:111-121.

Jeltsch, F., S. Milton, W. R. J. Dean, and N. van Rooyen. 1996. Tree spacing and coexistence in semi-arid savannas. Journal of Ecology 84:583-591.

Lavorel, S., J. Lepart, M. Debussche, J.-D. Lebreton, and J.-L. Beffy. 1994a. Small scale disturbances and the maintenance of species diversity in Mediterranean old fields. Oikos 70:455-473.

Lavorel, S., R. V. O'Neill, and R. H. Gardner. $1994 b$. Spatio-temporal dispersal strategies and annual plant species coexistence in a structured landscape. Oikos 71:75-88.

Lawton, R. O., and F. E. Putz. 1988. Natural disturbance and gap-phase regeneration in a wind-exposed tropical cloud forest. Ecology 69:764-777.

Levin, S. A. 1992. The problem of pattern and scale in ecology. Ecology 73:1943-1967.

Levin, S. A., and R. T. Paine. 1974. Disturbance, patch formation, and community structure. Proceedings of the National Academy of Sciences of the USA 71: 2744-2747.

Li, H., and J. F. Reynolds. 1994. A simulation experiment to quantify spatial heterogeneity in categorical maps. Ecology 75:2446-2455.

Martinsen, G. D., J. H. Cushman, and T. G. Whitham. 1990. Impact of pocket gopher disturbance on plant species diversity in a shortgrass prairie community. Oecologia (Berlin) 83:132-138.

Mateos, A. 1987. Spatial analysis of soil properties for crop modeling studies in Venezuela. M.Sc. thesis. Wageningen Agricultural University, Wageningen.
McConnaughy, K., and F. Bazzaz. 1990. Interactions among colonizing annuals: is there an effect of gap size? Ecology 71:1941-1951.

Milton, S. J. 1994. Growth, flowering and recruitment of shrubs in grazed and in protected rangeland in the arid Karoo, South Africa. Vegetatio 111:17-27.

1995a. Effects of rain, sheep and thephritid flies on seed production of two arid Karoo shrubs in South Africa. Journal of Applied Ecology 32:137-144.

- 1995b. Spatial and temporal patterns in the emergence and survival of seedlings in arid Karoo shrubland. Journal of Applied Ecology 32:145-156.

Milton, S. J., and W. R. J. Dean. 1990. Seed production in rangelands of the southern Karoo. South African Journal of Science 86:231-233.

Milton, S. J., W. R. J. Dean, and G. I. H. Kerley. 1992. Tierberg Karoo Research Centre: history, physical environment, flora and fauna. Transactions of the Royal Society of South Africa 48:15-46.

Moloney, K. A. 1986. Wave and nonwave regeneration processes in a subalpine Abies balsamea forest. Canadian Journal of Botany 64:341-349.

Moloney, K., and S. A. Levin. 1996. The effects of disturbance architecture on landscape-level population dynamics. Ecology 77:375-394.

Moloney, K., S. A. Levin, N. Chiariello, and L. Buttel. 1992. Pattern and scale in a serpentine grassland. Theoretical Population Biology 41:257-276.

Paine, R. T., and S. A. Levin. 1981. Intertidal landscape: disturbance and the dynamics of pattern. Ecological Monographs 51:145-178.

Pickett, S. T. A., and P. S. White, eds. 1985. The ecology of natural disturbance and patch dynamics. Academic Press, New York.

Platt, W. J. 1975. The colonization and formation of equilibrium plant species associations on badger disturbances in a tall-grass prairie. Ecological Monographs 45:285-305.

Reice, S. R. 1995. Nonequilibrium dynamics of biological community structure. American Scientist 82:424-435.

Ripley, B. D. 1976. The second-order analysis of stationary processes. Journal of Applied Probability 13:255266.

—. 1981. Spatial statistics. Wiley, New York.

Robertson, G. P., M. A. Huston, F. C. Evans, and J. M. Tiedje. 1988. Spatial variability in a successional plant community: pattern of nitrogen availability. Ecology 69:1517-1524.

Rossi, R., D. J. Mulla, A. G. Journel, and E. H. Franz. 1992. Geostatistical tools for modeling and interpreting ecological spatial dependence. Ecological Monographs 62:277-314.

Sato, K., and Y. Iwasa. 1993. Modeling of wave regenera- 
tion in subalpine Abies forests: population dynamics with spatial structure. Ecology 74:1538-1550.

Schlesinger, W. H., J. A. Raikes, A. E. Hartley, and A. F. Cross. 1996. On the spatial pattern of soil nutrients in desert ecosystems. Ecology 77:364-374.

Schwinning, S., and A. J. Parsons. 1996. A spatially explicit population model of stoloniferous N-fixing legumes in mixed pasture with grass. Journal of Ecology 84:815-826.

Silvertown, J., S. Holtier, J. Johnson, and P. Dale. 1992. Cellular automaton models of interspecific competition for space-the effect of pattern on process. Journal of Ecology 80:527-534.

Slatkin, M., and H. E. Arter. 1991. Spatial autocorrelation methods in population genetics. American Naturalist 138:499-517.

Smith, T. J., M. B. Robblee, H. R. Wanless, and T. W. Doyle. 1994. Mangroves, hurricanes, and lightning strikes: assessment of Hurricane Andrew suggests an interaction across two differing scales of disturbance. BioScience 44:256-262.

Upton, G., and B. Fingleton. 1985. Spatial data analysis by example. Vol. 1. Point pattern and quantitative data. Wiley, Chichester.

Venables, W. N., and B. D. Ripley. 1994. Modern applied statistics with S-Plus. Springer, New York.

Wiegand, T., and S. J. Milton. 1996. Vegetation change in semiarid communities, simulating probabilities and time scales. Vegetatio 125:169-183.

Wiegand, T., S. J. Milton, and C. Wissel. 1995. A simulation model for a shrub-ecosystem in the semi-arid Karoo, South Africa. Ecology 76:2205-2221.

Wiegand, T., W. R. J. Dean, and S. J. Milton. 1997. Simulated plant population responses to small scale disturbances in semi-arid shrublands. Journal of Vegetation Science 8:163-176.

Yeaton, R. I., and K. J. Esler. 1990. The dynamics of a succulent Karoo vegetation: a study of species association and recruitment. Vegetatio 88:103-113.

Zucchini, W., P. Adamson, and L. McNeill. 1992. A model of southern African rainfall. South African Journal of Science 88:103-109.

Associate Editor: Ilkka Hanski 